\title{
PATTERNS OF STUDENT INTERACTION IN CLARK-TROW SUBGROUPS
}

\author{
Sigrid M. Hutcheson and David W. Chapman, The University \\ of Michigan
}

Previous research on the Clark-Trow model has failed to provide evidence on whether students classified into the same Clark-Trow subgroup interact with one another or are even aware of their common orientation. Yet, this is a basic tenet of claims that these subgroups operate as campus subcultures. This study investigated whether students who self-select into the same Clark-Trow subgroup interact significantly more often with each other than they do with members of the other three subgroups. The results tend to disconfirm expectations based on the Clark-Trow model and suggest these subgroups do not operate as student subcultures.

Key words: student; interaction; Clark-Trow

The Clark-Trow model of student subculture (Clark and Trow, 1960) posits that two dimensions can be constructed along what are considered to be basic orientations toward college life, the student's identification with the institution and involvement with ideas. On the basis of students' placement on these two dimensions, Clark and Trow define four categories of orientation, which they designate as student subcultures: academic, collegiate, nonconformist, and vocational. This model holds a distinctive position in the literature because (1) it has been the object of considerable research and (2) it is the only typology of students which is claimed to be a model of college student subculture. This subculture claim has been disputed. Bolton and Kammeyer (1972) argue that the existence of interaction among persons within each subgroup, a necessary characteristic of a subculture, has never been demonstrated. They conclude, therefore, that the Clark-Trow model cannot be called a model of student subculture. The present study responds to

Address reprint requests to Dr. Sigrid Hutcheson, Office of the Dean, School of Education, The University of Michigan, Ann Arbor, Michigan 48109. 
the Bolton and Kammeyer criticism by investigating whether students within each subgroup interact significantly more often with each other than they do with members of the other three subgroups.

\section{REVIEW OF RESEARCH}

The Clark-Trow model has served as a research tool in over 30 studies since its appearance in 1960 . Some of these studies have attempted to validate the model by focusing on identifiable differences among persons subscribing to the four designated subgroups. These differences are personality variables (Kees, 1967; Kees and McDougall, 1971; Lange, Woodburn, and Miller, 1974; Pascarella and Terenzini, 1977), attitudes, behaviors, and other student characteristics (Lange, 1972; Terenzini and Pascarella, 1977; Warren, 1968). Closely related are studies that appear to have been undertaken on the assumption that the Clark-Trow model is a valid model. They, therefore, use the model to investigate how the members of the four groups compare on selected variables such as student values or participation in campus activities (Apostal, 1968; Brainard and Dollar, 1971; Kees, 1974; Maw, 1971; Ozaki, 1971; Walker, 1967; Williams, 1972).

The evident popularity and continued use of the Clark-Trow model has several explanations: (1) the available research supports the conclusion that subgroup affiliation is significantly related to other dimensions of student behavior and personality; (2) it is heuristically and conceptually appealing to persons who are familiar with the characteristics of college students; (3) it is a parsimonious classification of students; and (4) it is the only measure of subgroup affiliation that can be used by students to self-select directly into a subgroup. Most other measures involve greater inference and use students' responses to multiple items to group the students into a classification scheme.

Despite the widespread use of the Clark-Trow model in research on college students, a number of authors criticize the model for its conceptual weaknesses (Frantz, 1968). In particular, Bolton and Kammeyer (1972) assert that the model cannot properly be called a model of subcultures. They define subculture as a "normative value system held by some group of persons who are in persisting interaction, who transmit the norms and values to newcomers by some communication process, and who exercise some sort of social control to ensure conformity to the norms. Furthermore, the normative-value system of such a group must differ from the normative value system of the larger, the parent, or the dominant society" (Bolton and Kammeyer, 1972, pp. 381-382). They state that the two key elements in this definition that are not adequately met by the Clark-Trow model are (1) the re- 
quirement that the normative value system must be held by some group of people who are in persisting interaction, and (2) the requirement that the normative-value system must differ from the normative-value system of the larger society. Bolton and Kammeyer also suggest that although interaction within subcultures has "been asserted and sometimes been implied," it has not adequately been demonstrated. Feldman and Newcomb (1969) concur with this criticism when they cite the failure of research on the Clark-Trow model to provide evidence that shows whether students classified as the same type interact with one another or are even aware of their common orientation.

The present study responds to the Bolton-Kammeyer criticism. This study investigated whether students who self-select into the same Clark-Trow subgroups interact significantly more often with each other than they do with members of the other three subgroups. More specifically stated: Is there a probability greater than chance that a person will interact more with persons of his or her own subgroup than with persons not of that subgroup?

This study was undertaken because of its implications for research on college students, both for the planning and execution of the research as well as for the interpretation and application of results to decisionmaking situations. If the study verified that membership in a ClarkTrow subgroup does indeed correspond to certain interaction patterns, the body of research on subcultures would be available to enlighten the examination of such questions as how college student subcultures arise, how they are perpetuated, and how they function internally. In addition, a better understanding of student interaction would make it possible to begin to merge the student subculture literature with the literature on peer groups and their influence on students. Alternatively, if the study suggested that the Clark-Trow subgroups are not subcultures, researchers would need to be aware of the possibility of misapplication of sociological theory in research on student subgroups. Yinger (1960) has cautioned that such misapplications may lead to inappropriate research designs, inconsistent interpretation of the data, misleading conclusions, and erroneous programmatic recommendations.

\section{METHOD \\ Procedure}

College sophomores completed a questionnaire which asked them to select the Clark-Trow typology that described them best, to indicate the relative accuracy of each of the four typologies in describing them, and to name the three to five students with whom they spend the most time. In a second phase of the study, all 975 persons named in the first 
phase were asked to select the Clark-Trow typology that described them best.

\section{Sample}

Sample I was a simple random sample of 646 sophomores at a large eastern university. Responses were received from 478 sophomores for a response rate of $74 \%$. The 975 persons named as friends by respondents in Sample I composed Sample II. Of these, responses were received from 570 persons, a response rate of $58 \%$. The data analysis included only those 151 persons from Sample I for whom responses were received from three or more friends in Sample II. Chi-square goodness-of-fit was computed to determine the significance of differences between sample and population characteristics on the variables of sex and college of enrollment for these 151 subjects. No significant differences were found between sample and population on these two variables. Thus, this sample was judged representative of the population in terms of sex and college of enrollment.

\section{Instrumentation}

The four one-paragraph descriptions developed and validated by Peterson (1965) were presented to the Sample I subjects on a printed questionnaire (see Table 1). Students were asked to choose the paragraph that best described them and, further, to rate themselves on a 10-point scale across each of the four paragraphs to reflect how well each described their attitude. Finally, each student was asked to list the names and addresses of three to five students at the same university with whom he or she chose to spend the most time that semester and, also, to designate the approximate number of hours per week spent with each person. The questionnaire sent to Sample II subjects contained the same four paragraphs and the four 10-point rating scales.

\section{Analysis}

The research question asked whether there is a probability greater than chance that a student would interact more with students of his or her own subgroup than with students not of that subgroup. A chisquare test of association was used to assess the overall association between the subgroup of the person doing the naming and the subgroup of the person named. Additional analysis was done using the binomial distribution, which is concerned with the probability of "right" and "wrong"' choices, that is, choices of friends of the same subgroup as opposed to choices of friends not in the same subgroup. Thus, the 
TABLE 1. Clark-Trow Paragraphs (Peterson, 1965)

Attitude A. Persons holding this attitude emphasize education essentially as preparation for an occupational future. Social or purely intellectual phases of campus life are relatively less important, although certainly not ignored. Concern with extracurricular activities and college traditions is relatively small. These persons are usually quite committed to particular fields of study and are in college primarily to obtain training for careers in their chosen fields.

Attitude $B$. This attitude, while it does not ignore career preparation, assigns greatest importance to scholarly pursuit of knowledge and understanding, wherever the pursuit may lead. This attitude entails serious involvement in course work or independent study beyond the minimum required. Social life and organized extracurricular activities are relatively unimportant. Thus, while other aspects of college life are not to be forsaken, this attitude attaches greatest importance to interest in ideas, pursuit of knowledge, and cultivation of the intellect.

Attitude $C$. This attitude holds that besides occupational training and/or scholarly endeavor, an important part of college life exists outside the classroom, laboratory, and library. Extracurricular activities, living-group functions, athletics, social life, rewarding friendships, and loyalty to college traditions are important elements in one's college experience and necessary to the cultivation of the well-rounded person. Thus, while not excluding academic activities, this attitude emphasizes the importance of the extracurricular side of college life.

Attitude $D$. This is an attitude held by the student who either consciously rejects commonly held value orientations in favor of his own, or who has not really decided what is to be valued and is in a sense searching for meaning in life. There is often deep involvement with ideas and art forms both in the classroom and in sources (often highly original and individualistic) in the wider society. There is little interest in business or professional careers; in fact, there may be a definite rejection of this kind of aspiration. Many facets of the college-organized extracurricular activities, athletics, traditions, the college administration-are ignored or viewed with disdain. In short, this attitude may emphasize individualistic interests and styles, concern for personal identity, and often, contempt for many aspects of organized society.

analysis begins with the person doing the naming (Sample I) and asks: Given three choices, how often are these choices persons of the same subgroup? These observed frequencies can then be compared with the frequencies expected by chance on the basis of the distribution of possible choices in the population. 


\section{RESULTS}

The results of the chi-square test of association are reported in Table 2. The cells of Table 2 report the column percentages, indicating, for each of the four groups of students named, the percentage of the total number in that group named by students from each of the four groups. For example, of the 99 students.named who were in the vocational group, $37.4 \%$ were named by collegiates, $24.2 \%$ were named by other vocationals, and $19.2 \%$ each were named by academics and nonconformists. The results indicate that the likelihood of students being named by students of the same subgroup differed significantly from chance $\left(\chi^{2}=24.92, d f=9, \mathrm{p}<.003\right)$. This finding is consistent with the theoretical expectation of interaction within the Clark-Trow subgroups. However, a closer examination is necessary, because an overall significant chi-square does not indicate that the pattern of students naming others of the same subgroup differed significantly from chance for all four of the subgroups.

To examine more closely the association between the observed and expected values in each cell, the value of each cell's component was calculated as shown in Table 3, using the formula $\chi^{2}$ component $=$ $\left(f_{e}-f_{o}\right)^{2} / f_{e}$. The signs designated whether the observed absolute frequency was greater or less than the expected frequency. These individual values cannot be tested for significance, but can be used to indicate trends in the differences. On the diagonals, which indicate how often students were chosen by others of the same subgroup, the relation between $f_{o}$ and $f_{e}$ is positive, except for academics, which have a negative value. This means that vocationals, collegiates, and nonconformists were chosen by friends of their own group more than would be expected by chance. However, the small differences between observed and expected frequencies for vocationals chosen by vocationals and academics chosen by academics are too small to even be considered indicative of a trend, and as noted, the academics' interaction with other academics is less than expected by chance. Thus, the overall significance of the chi-square coefficient in Table 2 may not indicate significant interaction within all four of the subgroups. Table 3 offers additional insight. The two cells in which the observed frequency was substantially lower than the expected frequency were in the choice of collegiates by nonconformists and nonconformists by collegiates. While collegiates were chosen less often than expected by the other three groups, nonconformists were chosen more often than expected by all groups except collegiates. This seems to suggest that collegiates as a group differ from the other three groups in their interactions.

The distinctive character of the collegiate group was further tested by constructing contingency tables of collegiates and not-collegiates, vo- 


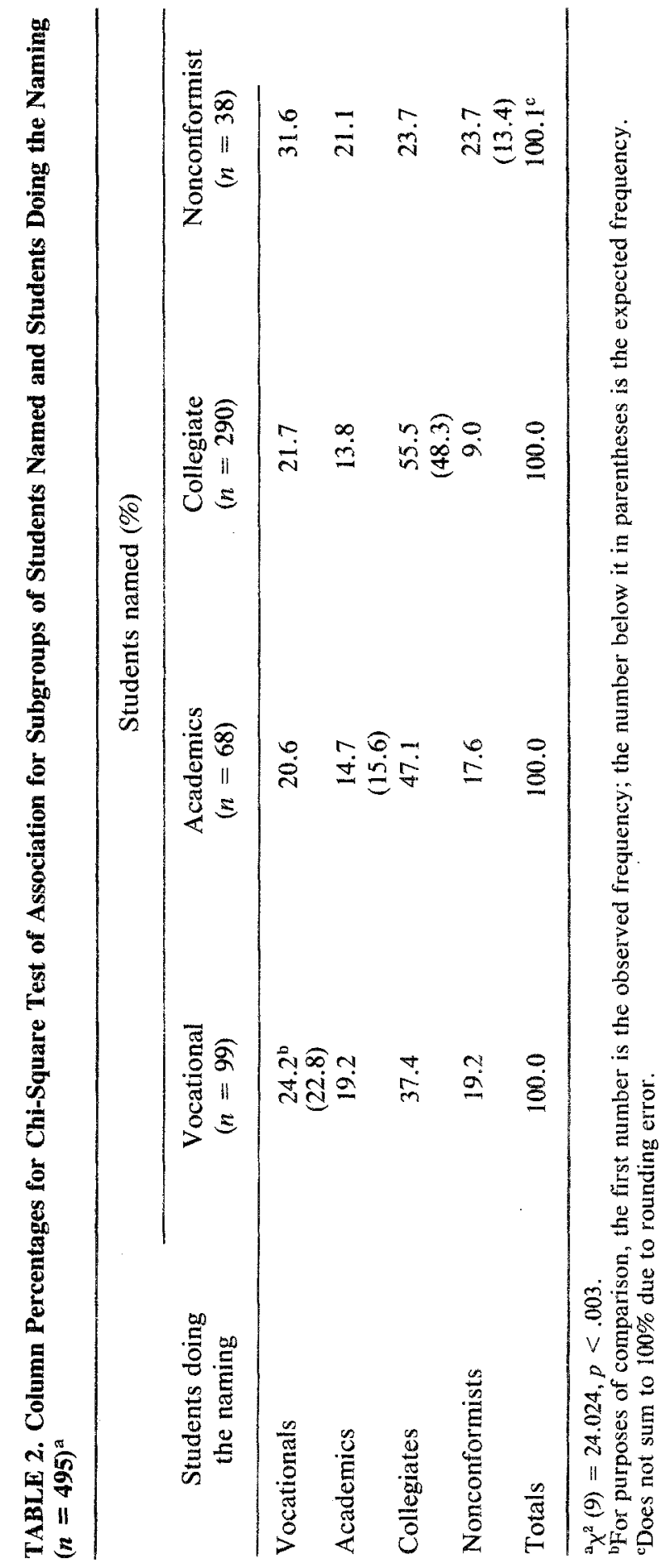




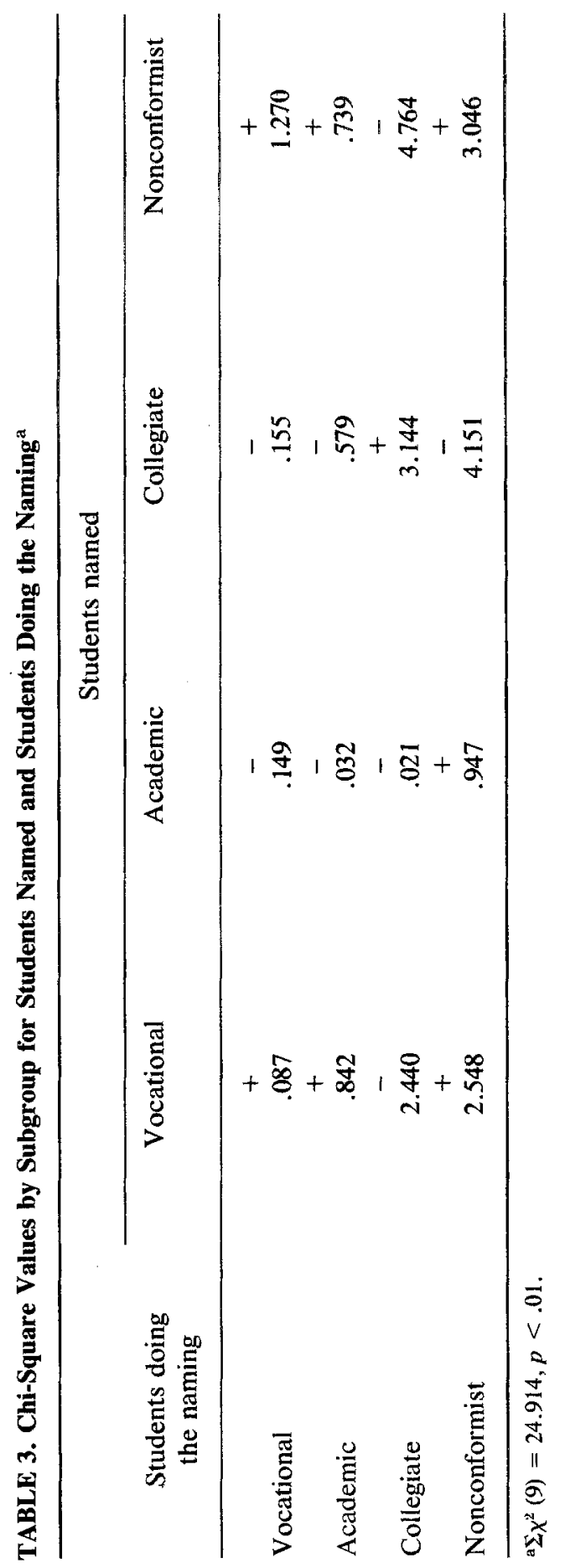


cationals and not-vocationals, academics and not-academics, and nonconformists and not-nonconformists. The only significant chi-square in these analyses was that for collegiates and not-collegiates (Table 4). This further substantiates the observation that collegiates are a distinctive group by showing that collegiates tend to be chosen by collegiates and not-collegiates tend to be chosen by not-collegiates. Hence, it appears that the likelihood of students being named by students of the same subgroup differed significantly from chance only for the collegiate group.

The results so far tend to disconfirm the expectation of subgroup interaction based on the Clark-Trow model. The four subgroups of that model do not appear to operate as subcultures, at least on the criteria of member interaction presented by Bolton and Kammeyer (1972).

Analysis additional to the chi-square was done using the binomial distribution. The binomial distribution is concerned with the probability of "right" choices based on the distribution of possible choices in the population. A right choice for this analysis was defined as a subject choosing a friend of the same subgroup and a "wrong" choice was therefore the choice of a friend of a different subgroup. The population distribution of Clark-Trow subgroups used to calculate the probability of right choices was based on the responses of all students from Sample I $(N=478)$ who indicated a subculture preference on the original questionnaire, as this group represented a random sample of the larger population.

While in the chi-square analysis each case was composed of a person named and the person doing the naming, for the binomial distribution each case consisted of the person doing the naming and all the persons named by that person for whom subgroup designation was known. The expected occurrence of $0,1,2$, and 3 right choices was calculated using the following formula:

$$
p(r \text { successes } ;, p)=\frac{\mathrm{N}}{r} p^{r} q^{N-r}
$$

where $p$ is the probability of a success, $q$ is the probability of a failure, $N$ is the number of independent trials, $r$ is the number of successes, and $N-r$ is the number of failures (Hays, 1972). The actual occurrence of right choices was determined from the group of respondents selected because they named at least three friends and because subgroup designations were obtained for at least three friends $(N=151)$. The expected and observed percentages are reported in Table 5, along with the $95 \%$ confidence interval which was constructed around the expected values. Examination of the cells (Table 5) shows that collegiates and nonconformists chose three friends of their own subgroup significantly more often than expected. However, the results for the non- 


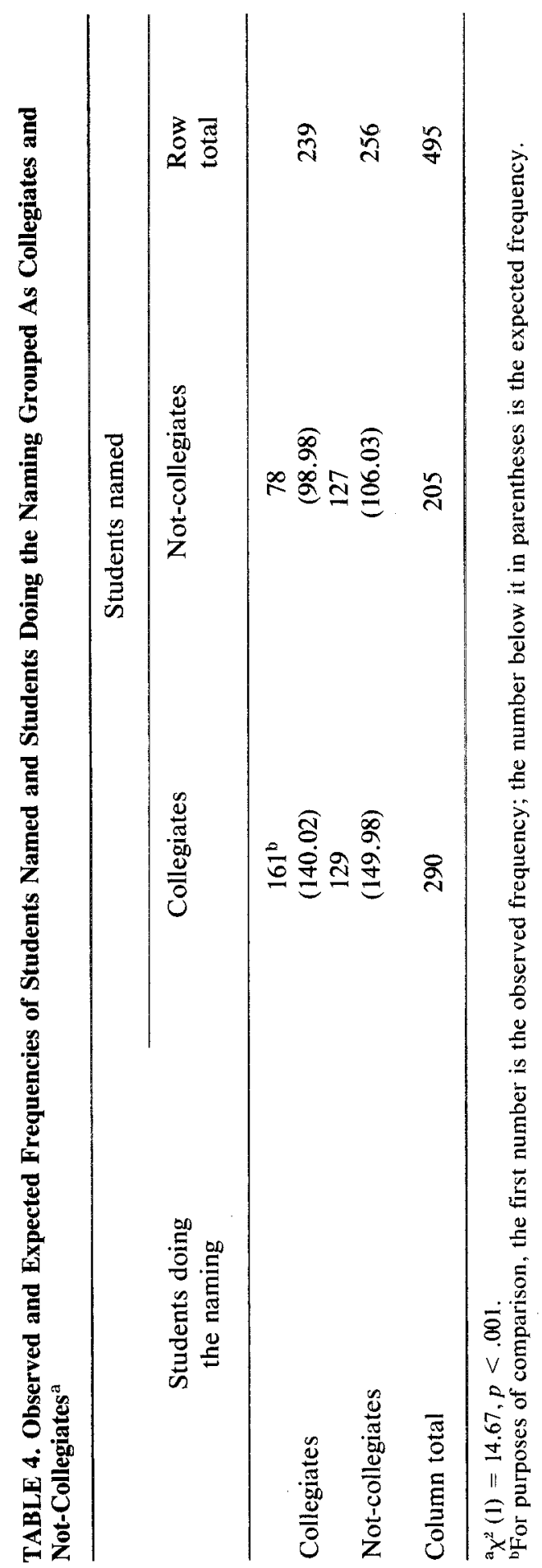




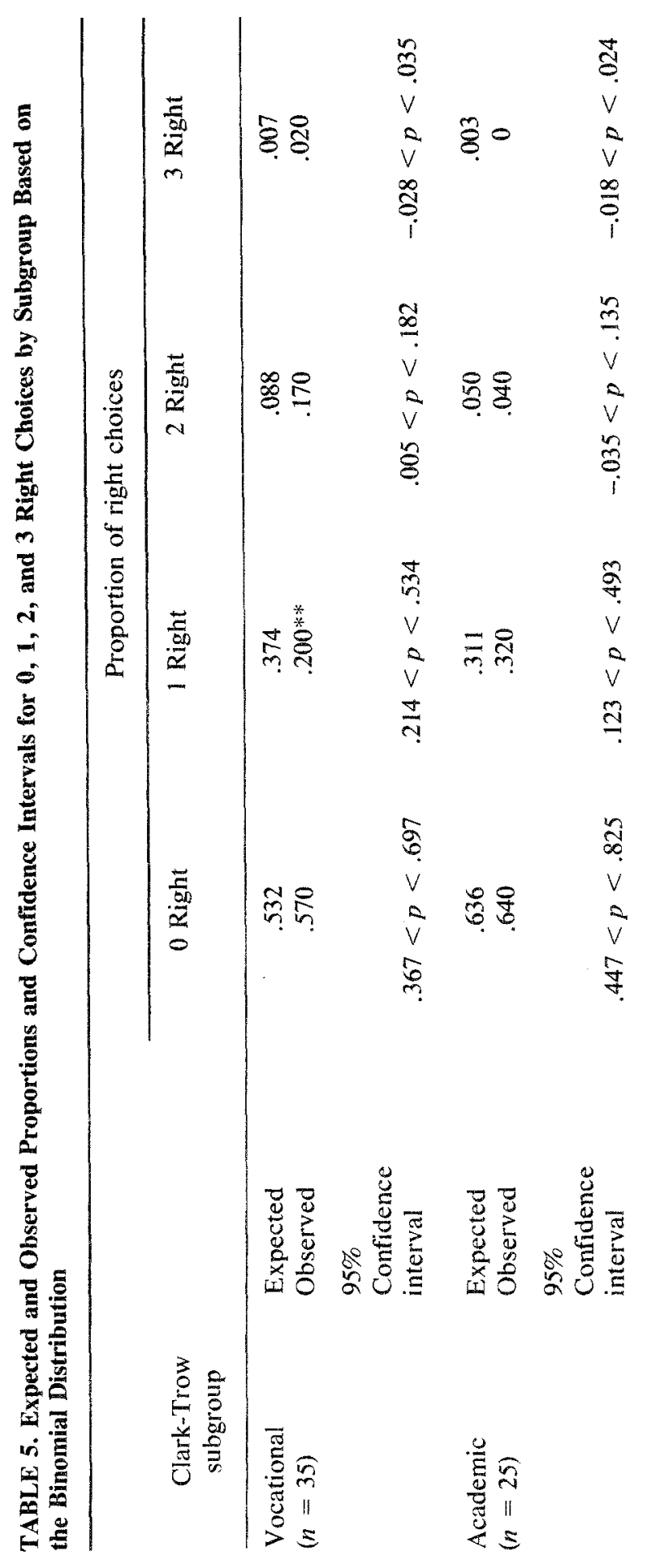




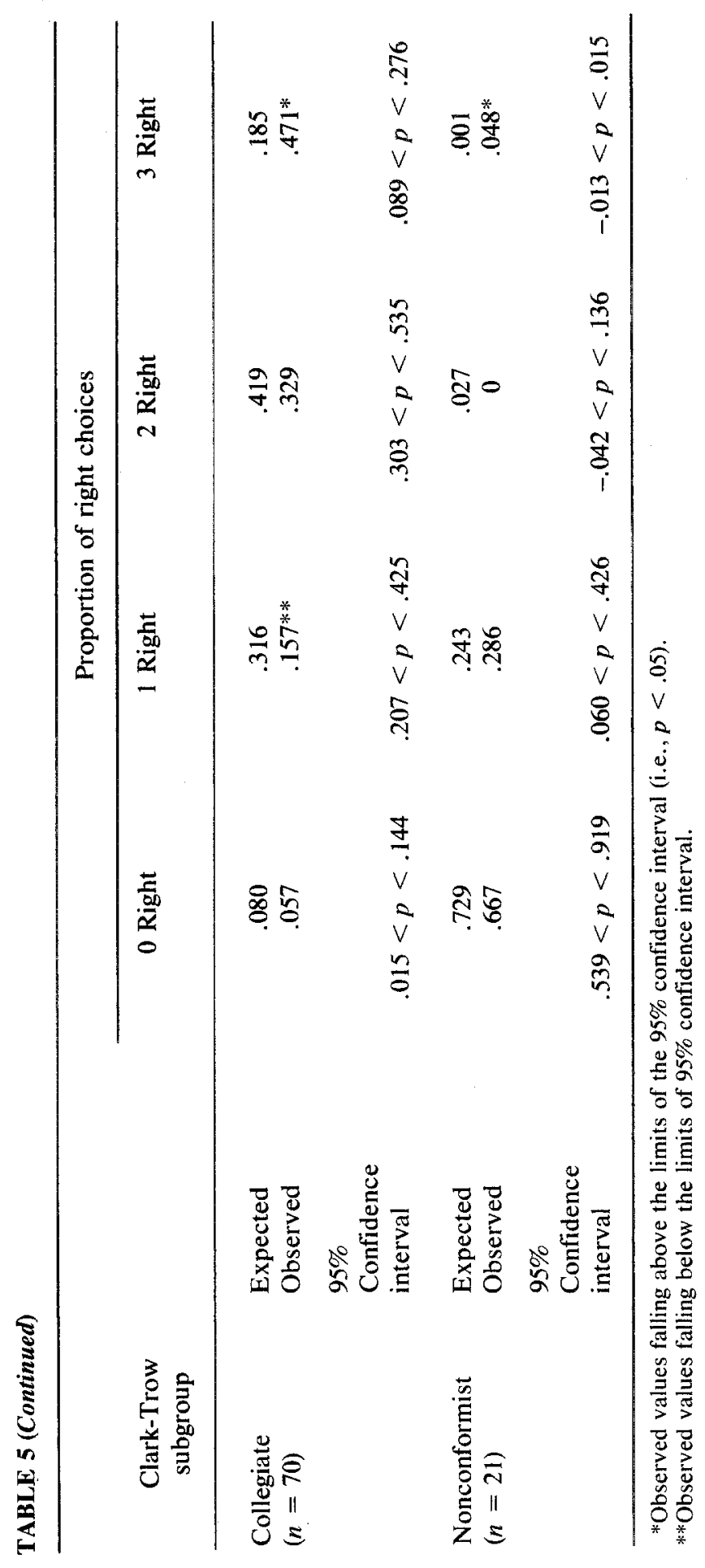


conformists should be disregarded, because only one person out of the sample of 21 nonconformists actually chose three friends who were also nonconformists. Hence, the results of the binomial distribution indicate that collegiates tend to name collegiates more often than expected by chance, whereas members of other groups do not tend to pick persons of the same group more often than by chance.

Thus, the findings of both the chi-square analysis and the binomial distribution tend to confirm the existence of interaction in the collegiate subgroup, but not in the other three subgroups.

\section{CONCLUSIONS}

Critics of the Clark-Trow model cite the lack of any evidence that there is interaction among members of the individual subgroups as one of the weaknesses of the model and argue that the subgroups cannot correctly be understood as subcultures. The results of this study tend to support the critics. It does not appear that persons within each subgroup tend to interact significantly more with each other than they do with persons from other subgroups, except for the collegiates. There was some interaction (though not statistically significant) among nonconformists and no evidence of interaction among vocationals and academics.

One interpretation of these results is that the group of students who identified themselves as collegiates is the only group that is accurately described by the Clark-Trow model. It may be that the other three group descriptions do not typify real groups of students but rather are simply composites of student characteristics.

Another possible interpretation is that there is a homogeneous group of students who constitute a dominant campus culture and a heterogeneous group of students whose values and attitudes differ in varied ways from those of the dominant group. In this study of students from Syracuse University, it appears that the dominant group is the collegiates, while the academics, vocationals, and nonconformists constitute a group which is more likely to interact with each other than with collegiates. This interpretation is supported by earlier findings of Stern (1970), in which he characterizes the environment of Syracuse University as predominantly collegiate.

Either interpretation suggests caution in using the Clark-Trow model. The subgroups do not appear to operate as subcultures, and previous research using the model should not be interpreted from a subculture framework. One cannot really say there are even separate peer groups, in the sense of exercising any special influence on each other. This rather severely limits the interpretations that can be offered for what 
differences have been observed among Clark-Trow subgroups in previous studies. How might the results of earlier studies be explained?

While considerable research suggests that students within the different subgroups do appear to differ on a number of variables, most of these variables have been measures of attitude, values, and/or personality (Pascarella and Terenzini, 1977; Apostal, 1968; Ozaki, 1971; Williams, 1972) rather than direct measures of behavior, particularly group behavior. Perhaps, then, there are more powerful explanations for these differences among groups than is provided by a sociological perspective. Since much of the earlier research has concentrated on differences along what might better be described as psychological variables, the importance of the Clark-Trow model is perhaps less in its sociological dimensions than its psychological dimensions. In this sense, it may be inappropriate to describe the four cells of the model as subgroups. Rather they should perhaps be designated as student orientations. Even within a psychological perspective, there may be a more powerful or parsimonious explanation for these differences than is provided by the Clark-Trow model. This would certainly be a direction for further investigation.

While this study investigated interaction in terms of subgroup designations of persons spending the time together, it did not address the question of the quality or intensity of this interaction. Since one of the purposes for investigating student interaction is to understand the effects of the interaction, further study of the different kinds of student interaction is another possible next step.

\section{REFERENCES}

Apostal, R. A. Student subcultures and personal values. Journal of College Student Personnel, 1968, 9, 34-39.

Bolton, C., and Kammeyer, K. C. W. Campus culture, role orientations and social types. In Kenneth Feldman (Ed.), College and student. New York: Pergamon Press, 1972.

Brainard, S. R., and Dollar, R. J. Personality characteristics of leaders identifying with different student subcultures. Journal of College Student Personnel, 1971, 12, 200-203.

Clark, B. R., and Trow, M. Determinants of college student subcultures. University of California, Berkeley: Center for the Study of Higher Education, 1960.

Feldman, K. A., and Newcomb, T. M. The impact of college on students (Vol. 1). San Francisco: Jossey-Bass, 1969.

Frantz, T. T. An investigation of college student subcultures (Doctoral dissertation, The University of Iowa, 1967). Dissertation Abstracts International, 1968, 28, 2984-A. (University Microfilms No. 68-00927).

Hays, W. Statistics. New York: Holt, Rinehart, and Winston, 1972. 
Kees, D. A study of college student subcultures using a typology (Doctoral dissertation, Washington State University, 1967). Dissertation Abstracts International, 1968, 29, 2985-A. (University Microfilms No. 68-703).

Kees, D. The Clark-Trow typology revisited. Journal of College Student Personnel, 1974, 15, 140-143.

Kees, D. J., and McDougall, W. P. A validation study of the Clark-Trow college subculture typology. Journal of College Student Personnel, 1971, 12, 193-199.

Lange, A. An analysis of Clark-Trow subtypes. Journal of College Student Personnel, 1972, 13, 347-351.

Lange, A., Woodburn, L. T., and Miller, W. G. OPI differences among Clark-Trow subgroups. Journal of College Student Personnel, 1974, 15, 498-501.

Maw, I. E. L. Student subcultures and activity involvement. Journal of College Student Personnel, 1971, 12, 62-66.

Ozaki, R. H. A comparative study of student subcultures and value systems in three state-supported institutions of higher education in Georgia (Doctoral dissertation, University of Georgia, 1971). Dissertation Abstracts International, 1972, 32, 3699-A. (University Microfilms No. 72-2524).

Pascarella, E. T., and Terenzini, P. T. Personality correlates of Clark-Trow orientations toward college; a construct validation. Journal of College Student Personnel, 1977, 18, 268-275.

Peterson, R. E. On a typology of college students. Research Bulletin 65-9. Princeton: Educational Testing Service, 1965.

Stern, G. G. People in context: measuring person-environment congruence in . education and industry. New York: John Wiley, 1970.

Terenzini, P. T., and Pascarella, E. T. An assessment of the construct validity of the Clark-Trow typology of college student subcultures. American Educational Research Journal, 1977, 14, 225-248.

Walker, J. R. A study of selected psychosocial correlates of college students (Doctoral dissertation, Oklahoma State University, 1967). Dissertation Abstracts International, 1968, 29, 4883-A. (University Microfilms No. 688516).

Warren, J. R. Student perceptions of college subcultures. American Educational Research Journal, 1968, 5, 213-232.

Williams, G. D. Clark-Trow viewpoints: associated personality traits and changes during the freshman year. Journal of College Student Personnel, $1972,13,341-346$.

Yinger, J. M. Contraculture and subculture. American Sociological Review, $1960,25,625-635$. 